\title{
In vitro anti-diabetic effects and phytochemical profiling of novel varieties of Cinnamomum zeylanicum (L.) extracts
}

\author{
W. A. Niroshani M. Wariyapperuma ${ }^{1}$, Sagarika Kannangara ${ }^{2}$, Yasanandana S. Wijayasinghe ${ }^{3}$, Sri Subramanium ${ }^{4}$, \\ Bimali Jayawardena ${ }^{\text {Corresp. } 1}$ \\ 1 Department of Chemistry, University of Kelaniya, Kelaniya, Western, Sri Lanka \\ 2 Department of Plant and Molecular Biology, University of Kelaniya, Kelaniya, Western, Sri Lanka \\ 3 Department of Biochemistry, University of Kelaniya, Ragama, Western, Sri Lanka \\ 4 Department of Chemistry, University of North Texas, Texas, United States \\ Corresponding Author: Bimali Jayawardena \\ Email address: bimalimadu123@gmail.com
}

Background: Diabetes mellitus type 2 (DMT2) is a common metabolic disorder in the world. Antidiabetic actions of phytochemicals from various medicinal herbs are considered as an alternative to the drugs used in the management of DMT2 in allopathic medicine due to adverse effects of synthetic drugs. $\alpha$-amylase and $\alpha$-glucosidase inhibitory potential and phytochemical profiling were investigated in aqueous extracts of two new Cinnamomum zeylanicum accessions, namely C. zeylanicum Sri Wijaya (SW), C. zeylanicum Sri Gemunu (SG) and commercially available C. zeylanicum (CC).

Methods: Microwave Digestion (MD), Pressurized Water Extraction (PWE), Steam Distillation (SD), Solvent Extraction (SE), Decoction Water Extraction (DWE) and Infusion Water Extraction (IWE) methods were used to prepare Cinnamon quill extracts. Total phenolic content (TPC, Folin-Ciocalteu method) and Proanthocyanidin content (PC, vanillin assay), $\alpha$-amylase and $\alpha$-glucosidase inhibition of Cinnamon extracts were determined spectrophotometrically. The $\alpha$-amylase and $\alpha$-glucosidase inhibition were reported in terms of $\mathrm{IC}_{50}$ value. The phytochemical profiling was accomplished by GC-MS technique.

Results and discussion: Lowest $\mathrm{IC}_{50}$ values were observed in PWE and DWE of SW. Highest PC and TPC was also observed in PWE and DWE of SW. Pressured water and decoctions are promising methods for the extraction of antidiabetic constituents from Cinnamon. Benzoic acid, Cinnamyl alcohol, Benzyl alcohol, and 4-Allyl-2,6-dimethoxyphenol were identified as major compounds in SW extracts. These compounds are believed to be responsible for strong enzyme inhibitory activity of the extracts.

Conclusions: This is the first study to explore the use of pressured and decoctions water to extract antidiabetic phytochemicals from Cinnamon. The extensive metabolite profiling of novel SW and SG extracts and comparison of that with commercially available CC are reported for the first time in this study. The $C$. zeylanicum, SW accession holds some promise in the management of diabetes. 
1 In vitro anti-diabetic effects and phytochemical profiling of novel varieties of Cinnamomum

2 zeylanicum (L.) extracts

3 W. A. Niroshani M. Wariyapperuma ${ }^{1}$, Sagarika Kannangara ${ }^{2}$, Yasanandana S. Wijayasinghe ${ }^{3}$,

4 Sri Subramanium ${ }^{4}$ and Bimali Jayawardena ${ }^{1}$

$5 \quad{ }^{1}$ Department of Chemistry, University of Kelaniya, Kelaniya, Western, Sri Lanka

6 2Department of Plant and Molecular Biology, University of Kelaniya, Kelaniya, Western, Sri

$7 \quad$ Lanka

$8{ }^{3}$ Department of Biochemistry, University of Kelaniya, Ragama, Western, Sri Lanka

$9 \quad{ }^{4}$ Department of Chemistry, University of North Texas, United States

11 Corresponding Author:

12 Bimali Jayawardena ${ }^{1}$

${ }^{1}$ Department of Chemistry, Faculty of Science, University of Kelaniya, Dalugama, Sri Lanka

15 Email address: bimalimadu123@gmail.com 


\section{Abstract}

Background: Diabetes mellitus type 2 (DMT2) is a common metabolic disorder in the world. Anti-diabetic actions of phytochemicals from various medicinal herbs are considered as an alternative to the drugs used in the management of DMT2 in allopathic medicine due to adverse effects of synthetic drugs. $\alpha$-amylase and $\alpha$-glucosidase inhibitory potential and phytochemical profiling were investigated in aqueous extracts of two new Cinnamomum zeylanicum accessions, namely C. zeylanicum Sri Wijaya (SW), C. zeylanicum Sri Gemunu (SG) and commercially available C. zeylanicum (CC).

Methods: Microwave Digestion (MD), Pressurized Water Extraction (PWE), Steam Distillation (SD), Solvent Extraction (SE), Decoction Water Extraction (DWE) and Infusion Water Extraction (IWE) methods were used to prepare Cinnamon quill extracts. Total phenolic content (TPC, Folin-Ciocalteu method) and Proanthocyanidin content (PC, vanillin assay), $\alpha$-amylase and $\alpha$-glucosidase inhibition of Cinnamon extracts were determined spectrophotometrically. The $\alpha$ amylase and $\alpha$-glucosidase inhibition were reported in terms of $\mathrm{IC}_{50}$ value. The phytochemical profiling was accomplished by GC-MS technique.

Results and discussion: Lowest $\mathrm{IC}_{50}$ values were observed in PWE and DWE of SW. Highest PC and TPC was also observed in PWE and DWE of SW. Pressured water and decoctions are promising methods for the extraction of antidiabetic constituents from Cinnamon. Benzoic acid, Cinnamyl alcohol, Benzyl alcohol, and 4-Allyl-2,6-dimethoxyphenol were identified as major compounds in SW extracts. These compounds are believed to be responsible for strong enzyme inhibitory activity of the extracts.

Conclusions: This is the first study to explore the use of pressured and decoctions water to extract anti-diabetic phytochemicals from Cinnamon. The extensive metabolite profiling of 
42 novel SW and SG extracts and comparison of that with commercially available CC are reported

43 for the first time in this study. The C. zeylanicum, SW accession holds some promise in the

44 management of diabetes.

45

46

47

48

49

50

51

52

53

54

55

56

57

58

59

60

61

62

63

64

\section{Introduction}

Diabetes is a leading metabolic disorder with multiple health effects and complications (Schwartz et al., 2016). More than $90 \%$ of diabetic patients are suffering from diabetes mellitus type 2 (DMT2). Modern sedentary lifestyle, unhealthy food habits and obesity are key factors responsible for the development of DMT2 (William et al., 2019). These factors may also contribute to generate a state of oxidative stress by producing reactive oxygen species. The oxidative stress condition can cause hyperglycemia by affecting the insulin secretion and the action (Akash et al., 2011). Hence, the use of antioxidant based therapies in treating DMT2 and its complications has been emphasized (Rahimi-Madiseh et al., 2016). Furthermore, there is a growing interest to develop herbal drugs and their bioactive compounds as an alternate treatment for DMT2 due to the serious side effects associated with synthetic therapeutic agents (William et al., 2019). One treatment strategy applicable for diabetes mellitus is the inhibition of enzymes involved in the hydrolysis of carbohydrates in the digestive tract. Number of bioactive ingredients in medicinal plants have been found to inhibit $\alpha$-amylase and $\alpha$-glucosidase enzymes(Funke \& Melzig, 2006). $\alpha$-amylase breaks down the large and insoluble starch molecules into absorbable disaccharides. $\alpha$-glucosidase helps to convert oligosaccharides and disaccharides into monosaccharaides (Kazeem, Ogunbiyi \& Ashafa, 2013). The inhibitors of these enzymes restrict the digestion of dietary carbohydrates, thus subsequently prevent the absorption of simple sugars leading to low postprandial glucose levels. In addition, herbal extracts are also rich in natural antioxidants, which may help to reduce the risk of developing DMT2 (Zaid et al., 2015). 
Cinnamomum zeylanicum (Family Lauraceae) which is also known as Ceylon Cinnamon or true Cinnamon is an indigenous plant in Sri Lanka. Recent studies have shown many beneficial health effects of Cinnamon such as anti-hypertensive effect, anti-inflammatory properties, anti-microbial activity, blood glucose control, reducing the risk of cardiovascular disease and colonic cancer (Mahmoodnia, Aghadavod \& Rafieian-Kopaei, 2017)(Ouattara et al., 1997; Khan, et al., 2003; Shen et al., 2010).

Eight Cinnamon species, categorized on the basis of the taste of the bark, have been identified in Sri Lanka (Azad et al., 2015). Among them only Cinnamomum zeylanicum is grown commercially. Recently, two accessions of Cinnamomum zeylanicum named as "Sri Wijaya" and "Sri Gemunu" have been developed for commercial cultivation with improved chemical profiles and yields (https://www.lankabusinessonline.com/sri-lanka-develops-new-Cinnamon-varieties/2020.04.07; Azad et al., 2015). Yet, scientific evidence on biological activities and the anti-diabetic properties of these novel Cinnamon varieties have not been explored. This study was conducted with the objective of to evaluate six types of aqueous extracts of SW and SG Cinnamon quill varieties and commercially available CC quills for their in vitro anti-diabetic activities and compare them with the standard hypoglycemic drug Acarbose. The study was further extended to explore the phytochemical profiles of different Ceylon Cinnamon extracts.

\section{Materials \& Methods}

\section{Collection of plant materials and preparation of extracts}

Commercial Cinnamomum zeylanicum dried quills $(1 \mathrm{~kg})$ were collected from Dassanayake Walauwa Cinnamon plantation, Nape, Kosgoda, Southern Province in Sri Lanka. Sri Wijaya and Sri Gemunu Cinnamon quills (2 kg per each) were collected from Cinnamon Research Station, Palolpitiya, Thihagoda, Southern Province, Sri Lanka. The collected samples were transported in 
88 sealed, sterilized polythene bags to the laboratory at University of Kelaniya, Sri Lanka. The

89 samples were stored in a refrigerator $\left(2-8^{\circ} \mathrm{C}\right)$ until use.

90 Cinnamon accessions were authenticated by a botanist at the Department of Botany, University of

91 Kelaniya. The voucher specimen of "Sri Wijaya" and "Sri Gemunu" accessions were deposited at

92 the publicly available herbarium, Department of Botany, the University of Kelaniya, Sri Lanka

93 under the family Lauraceae (Deposition numbers are CIN-SW-001 and CIN-SG-002 respectively

94 for "Sri Wijaya" and "Sri Gemunu" accessions).

95 Cinnamon quills (10 g) were pulverized using a $0.50 \mathrm{~mm}$ mesh. For the microwave digestion

96 (MD), the sample (10 g) was digested with distilled water $(80 \mathrm{~mL})$ for 30 minutes using a

97 microwave digester (mass 6 instrument, vessel type Mars Xpress). Pulverized Cinnamon quills (10

g) were extracted with pressurized water $(200 \mathrm{~mL}$ at $0.098 \mathrm{MPa}$, for 10 minutes $)$ for the preparation of pressurized water extract (PWE). Quills of Cinnamon (40 g) were extracted by traditional steam distillation (SD) and $10 \mathrm{~g}$ were extracted by solvent extraction (SE) using 75\% ethanol (Wong, 2014; Lee et al., 2018). For the preparation of decoction water extract (DWE), Cinnamon quills (10 g) were boiled with water $(200 \mathrm{~mL})$ until the volume was reduced to $1 / 8$. Ten grams of Cinnamon powder was mixed with boiled water $(200 \mathrm{~mL})$ and that was allowed to stand for five minutes to obtain the infusion water extract (IWE). The MD, PWE, DWE, and IWE were filtered through Whatman 1 filter paper and concentrated under vacuum at $45^{\circ} \mathrm{C}$ and further dried by passing a stream of $\mathrm{N}_{2}$ air. The percentage yield was calculated and stored at $-20{ }^{\circ} \mathrm{C}$. The volatile compounds from SD were separated from the aqueous layer three times using hexane $(30 \mathrm{~mL})$. The volatiles were concentrated by using rotary evaporator (IKA ${ }^{\circledR}$ RV 10 basic, Germany). The percentage yield of the resultant oleoresin was calculated and the oleoresin was stored at $-20{ }^{\circ} \mathrm{C}$. 


\section{$\alpha$ - glucosidase inhibitory activity}

111 The $\alpha$-glucosidase inhibition assay (Apostolidis \& Lee, 2010) was used to determine the in vitro 112 anti-diabetic properties of Cinnamon extracts. Varying concentrations $(12.5 \mu \mathrm{g} / \mathrm{mL}-400 \mu \mathrm{g} / \mathrm{mL})$

113 of Cinnamon quill extract $(100 \mu \mathrm{L})$ and $0.1 \mathrm{M}$ phosphate buffer, $\mathrm{pH} 6.8(100 \mu \mathrm{L})$ with $\alpha$ 114 glucosidase enzyme solution ( $1 \mathrm{Unit} / \mathrm{mL}$ ) were incubated in 96 well plates at $37^{\circ} \mathrm{C}$ for 10 minutes. 115 After pre-incubation, $2.5 \mathrm{mM}$ 4-Nitrophenyl $\beta$-D-glucopyranoside (pNPG) solution $(20 \mu \mathrm{L})$ in $1160.1 \mathrm{M}$ phosphate buffer, $\mathrm{pH} 6.8$ was added to each well. The reaction mixture was incubated at 37 $117{ }^{\circ} \mathrm{C}$ for 20 minutes. After the incubation, the absorbance at $405 \mathrm{~nm}$ was recorded by the micro plate 118 reader (Spectra Max M5, Molecular Devices, CA, USA). Acarbose was used as the positive control $119(12.5 \mu \mathrm{g} / \mathrm{mL}-400 \mu \mathrm{g} / \mathrm{mL})$. The solvent alone was used as the blank in the assay. The $\mathrm{IC}_{50}$ values 120 were calculated as follows;

121 Inhibition (\%) $=1-\left\{\frac{A_{\text {sample }}}{A_{\text {control }}}\right\} \times 100$

122 Where, $\mathrm{A}_{\text {sample }}$ and $\mathrm{A}_{\text {control }}$ were defined as absorbance of the sample and the control (blank) 123 respectively.

\section{a- Amylase inhibitory activity}

125 The $\alpha$-amylase inhibition assay (Ranilla et al., 2010) was also used to evaluate the anti-diabetic properties of Cinnamon extracts. Various concentrations $(12.5 \mu \mathrm{g} / \mathrm{mL}-400 \mu \mathrm{g} / \mathrm{mL})$ of the extract

$127(100 \mu \mathrm{L})$ and $0.02 \mathrm{M}$ sodium phosphate buffer, pH $6.9(100 \mu \mathrm{L})$, amylase enzyme solution $(0.5$ $\mathrm{mg} / \mathrm{ml}, 10 \mu \mathrm{L})$ were incubated at room temperature $\left(28 \pm 2^{\circ} \mathrm{C}\right)$ for 10 minutes in a test tube. After pre-incubation, $100 \mu \mathrm{L}$ of $1 \%$ starch in $0.02 \mathrm{M}$ sodium phosphate buffer, $\mathrm{pH} 6.9$ was added to each tube. The reaction mixtures were incubated at room temperature $\left(28 \pm 2{ }^{\circ} \mathrm{C}\right)$ for 10 minutes. The reaction was quenched by adding Dinitrosalicylic acid color reagent $(100 \mu 1)$. The test tubes were 
132 boiled in a water bath until the yellowish orange color was developed and then the tubes were

133 allowed to cool. The reaction mixture was diluted with distilled water $(5.00 \mathrm{~mL})$, and a $250 \mu \mathrm{L}$

134 aliquot of the reaction mixture was transferred into a 96 well micro titer plate. The absorbance at

$135540 \mathrm{~nm}$ was measured using a micro plate reader (Spectra Max M5, Molecular Devices, CA, USA).

136 Acarbose was used as the positive control $(12.5 \mu \mathrm{g} / \mathrm{mL}-400 \mu \mathrm{g} / \mathrm{mL})$.

137 The $\alpha$-amylase inhibitory activity of each extract is expressed as percent inhibition which was 138 calculated as follows:

139

Inhibition $(\%)=1-\left\{\frac{A_{\text {sample }}}{A_{\text {control }}}\right\} \times 100$

140 Where, $\mathrm{A}_{\text {sample }}$ and $\mathrm{A}_{\text {control }}$ are defined as absorbance of the sample and the control respectively.

141 Control was conducted without adding the extract.

\section{Total phenolic content (TPC) determination assay}

143 The Folin-Ciocalteu method (Wang et al., 2012) was used to determine the TPC. The plant extract

144 (3.00 mg extract dry weight) was mixed with $10 \%$ Folin-Ciocalteu reagent $(5.00 \mathrm{~mL})$ and the 145 mixture was incubated at room temperature $\left(28 \pm 2^{\circ} \mathrm{C}\right)$ for five minutes. Sodium carbonate $(4.00$ $146 \mathrm{~mL}, 7.5 \% \mathrm{v} / \mathrm{w}$ ) was added and the mixture was allowed to stand for one hour at room temperature $147\left(28 \pm 2{ }^{\circ} \mathrm{C}\right)$. The absorbance was measured at $765 \mathrm{~nm}$ using a UV-visible spectrophotometer. A 148 calibration curve for Gallic acid in concentrations from $0.02 \mathrm{mg} / \mathrm{mL}$ to $1.00 \mathrm{mg} / \mathrm{mL}\left(\mathrm{R}^{2}=0.99\right)$ 149 was used to interpolate results of the TPC and the results were expressed as gallic acid equivalents 150 (GAE) $\mathrm{mg} / \mathrm{g}$ dried extract. 


\section{Proanthocyanidine content (PC) determination assay}

152 Vanillin assay was used to determine the PC. The extract ( $3.00 \mathrm{mg}$ extract dry weight) of

153 Cinnamon quills was mixed with $1 \% \mathrm{w} / \mathrm{v}$ vanillin solution in $7 \mathrm{M} \mathrm{H}_{2} \mathrm{SO}_{4}(4.00 \mathrm{~mL})$ and they were

154 incubated at room temperature $\left(28 \pm 2{ }^{\circ} \mathrm{C}\right)$ for 15 minutes. After the incubation, the absorbance

155 was measured at $500 \mathrm{~nm}$. Catechine was used as the standard. A calibration curve for catechin in

156 concentrations from $0.05 \mathrm{mg} / \mathrm{mL}$ to $0.25 \mathrm{mg} / \mathrm{mL}\left(\mathrm{R}^{2}=0.99\right)$ was used to interpolate the results of

157 the PC and the results were expressed as catechin equivalents (Toda, 2005).

\section{GC-MS Analysis}

159 Crude extract $(4.00 \mathrm{mg})$ was dissolved in $1.00 \mathrm{~mL}$ of hexane and the samples were filtered using 160 a nylon filter $(0.45 \mu \mathrm{m}$ pore size $)$. A $0.7 \mu \mathrm{L}$ aliquot of the above was injected in the split less mode 161 into a GC/MS 7890B Gas Chromatograph (Agilent, American) equipped with a 5977B mass 162 spectrometer (Agilent, American). A fused silica capillary Agilent Technology HP-5 (5\% phenylmethyl polysiloxane) column $(30 \mathrm{~m} \times 0.25 \mathrm{~mm} \times 0.25 \mu \mathrm{m})$ was used for the separation. The injector temperature was $250^{\circ} \mathrm{C}$. The initial temperature was kept at $40{ }^{\circ} \mathrm{C}$, for 3 minutes and the temperature was gradually increased to $220{ }^{\circ} \mathrm{C}$ at the rate of $4{ }^{\circ} \mathrm{C} \mathrm{min}-1$ and was then held for 2 $\min ^{-1}$ and held for 3 minutes at $230^{\circ} \mathrm{C}$. The Post run was at $235^{\circ} \mathrm{C}$ held for 3 minutes. The Total GC running time was 54.25 minutes. Helium was used as the carrier gas at a constant flow rate of $1.0 \mathrm{~mL} \mathrm{~min} \mathrm{~m}^{-1}$ at the split-less mode. EI was used as the ion source, and the ion source temperature was $230{ }^{\circ} \mathrm{C}$. The sector mass analyzer was set to scan from 40 to $650 \mathrm{amu}$ The volatile components

171 of the extracts were identified using mass spectral data, with computer assisted matching with 172 WILEY 275 and National Institute of Standards and Technology (NIST6.0) libraries. 


\section{Statistical analysis}

174 All results are expressed as mean \pm SD of triplicate assays. Statistical analyses were performed 175 using Microsoft Office Excel (2013) and Graph Pad Prism 7 statistical package (GraphPad 176 Software, USA). Significant differences among the data were analyzed by the SPSS Statistical 177 computer package (IBM $®$ SPSS $®$ Statistics Version 23, USA). The results were analyzed using 178 one-way ANOVA test followed by Dunnett/Tukey test for multiple comparisons, paired sample t179 test and determination of significance level. Group means were considered to be significantly 180 different at $P<0.05$.

\section{Results}

\section{Extract yield analysis}

183 The yield of Cinnamon quill extracts ranged from $0.42 \% \pm 0.03 \%$ to $2.19 \% \pm 0.25 \%$ for SW; $0.39 \% \pm 0.02 \%$ to $1.90 \% \pm 0.05 \%$ for SG and $0.15 \% \pm 0.00 \%$ to $1.26 \% \pm 0.08 \%$ for CC (Fig. 1 ).

The results indicated that there was significant difference $(p<0.05)$ in the yield of the extracts depending on the Cinnamon accessions and the extraction methods. The highest yield was obtained 187 from SW, PWE $(2.19 \% \pm 0.25 \%)$. Microwave digestion gave the lowest yield in all Cinnamon varieties $(0.42 \% \pm 0.03 \%$ for $\mathrm{SW} ; 0.39 \% \pm 0.02 \%$ for $\mathrm{SG}$ and $0.15 \% \pm 0.00 \%$ for $\mathrm{CC})$.

\section{$\alpha$-glucosidase and $\alpha$-amylase enzyme inhibitory activity}

190 The $\alpha$-glucosidase and $\alpha$-amylase enzyme inhibitory activities of cinnamon extracts are expressed 191 in terms of $\mathrm{IC}_{50}$ values, and the lower $\mathrm{IC}_{50}$ is an indicative of a stronger inhibition. SW, PWE 192 exhibited the significantly highest inhibitory activity $(P<0.05)$ for $\alpha$-glucosidase and $\alpha$-amylase 193 (42 $\pm 8 \mu \mathrm{g} \mathrm{mL}^{-1}$ and $78 \pm 7 \mu \mathrm{g} \mathrm{mL}^{-1}$, respectively) followed by SW, DWE (116 $\pm 17 \mu \mathrm{g} \mathrm{mL}^{-1}$ and $194132 \pm 11 \mu \mathrm{g} \mathrm{mL}^{-1}$, respectively). The inhibition of these extracts were comparable with the positive control, Acarbose $\left(173 \pm 7 \mu \mathrm{g} \mathrm{mL}^{-1}\right.$ and $95 \pm 4 \mu \mathrm{g} \mathrm{mL}^{-1}$ respectively) as in Table 1. 
197 Total phenolic content was expressed as mg GAE/g and PC was expressed as mg of catechin 198 equivalent $\mathrm{g}^{-1}$. In comparing the TPC and the PC of extracts, the highest TPC and the highest PC 199 were obtained for the DWE $(2.24 \pm 0.00 \mathrm{mg} \mathrm{GAE} / \mathrm{g}$ and $40.05 \pm 0.10 \mathrm{mg}$ of catechin equivalent $200 \mathrm{~g}^{-1}$ respectively) for SW. The extracts obtained by using SD had the lowest TPC and PC for SW $201\left(0.21 \pm 0.01 \mathrm{mg} \mathrm{GAE} / \mathrm{g}\right.$ and $1 \pm 0.01 \mathrm{mg}$ of catechin equivalent $\left.\mathrm{g}^{-1}\right)$ as in Table 2.

\section{GC-MS analysis}

203 (E)- Cinnamaldehyde, was the dominant compound in CC, SW and SG extracts prepared using 204 steam distillation, Infusion and solvent extraction respectively (Table 3). In pressured water extracts of SW and SG; Benzoic acid (1.6\%, 15.49\%), (E)-Cinnamaldehyde (5.8\%, 5.46\%), Cinnamyl alcohol (32.44\%, 40.08\%), and 4-Allyl-2,6-dimethoxyphenol (10.2\%, 12.71\%) were the major compounds present (Table 3).

Benzoic acid $(2.58 \%, 22.51 \%)$, (E)-Cinnamaldehyde $(34.6 \%, 5.58 \%)$, Trans-cinnamic acid (16.86\%, 4.51\%), O-Methoxy-cinnamaldehyde (2.04\%, 2.14\%), Cinamyl alcohol (21.3\%, 42.48\%), and 4-Allyl-2,6-dimethoxyphenol (3.24\%, 8.79\%) were the major compounds present in SG and SW accession bark prepared as a decoction. Benzoic acid and Cinnamyl alcohol were not detected in CC, PWE and DWE. 4-Allyl-2,6-dimethoxyphenol (1.79\%, 1.05\%) was seen as a minor constituent in $\mathrm{CC}$ extracted using pressured water and as a decoction (Table 3).

214 Twenty seven chemical components were identified for the first time in SW; PWE. Benzcatechin

Methyladamantane (2.14\%), 1-(2'-hydroxyphenyl)prop-2-en-1-ol (0.71\%), 1,3,5-benzenetriol 
219 present only PWE of SW. These compounds and 4-Allyl-2,6-dimethoxyphenol were detected for

220 the first time in any Cinnamon accessions (Table 3).

\section{Discussion}

222 Cinnamon incorporated foods and nutraceuticals are popular choice in Sri Lanka due to the belief 223 of its anti-diabetic properties. However, the anti-diabetic effect of two selected cinnamon 224 accessions, Cinnamomum zeylanicum Sri Wijaya and Cinnamomum zeylanicum Sri Gemunu have

225

226

227

228

229

230

231

232

233

234

235 not been scientifically verified and not well understood. In the current study, water extracts were prepared from selected Ceylon Cinnamon accessions to determine the anti-diabetic activity. The $\alpha$-glucosidase/ $\alpha$-amylase inhibitory activities, total phenolic compounds, and proanthocyanidin content were evaluated in aqueous extracts of Cinnamomum zeylanicum and the chemical profiles were identified using GC-MS.

The yield of extracts prepared using different methods from variety of Cinnamon quill samples are presented in figure 1. The yield of the bark essential oil of novel Cinnamon accessions prepared using hydro distillation have been reported previously for SW (1.25\%), SG (1.49) (Ariyarathne, Weerasuriya \& Senarath, 2018; ), and CC (1.2\%) (Jayawardena \& Smith, 2010). Higher yield was reported for Sri Gemunu Cinnamon accessions $(3.4 \%$. v/w) than for the Sri Wijaya by the same distillation method in another study (Lokuge et al. 2018). In the current study, the percent yields obtained for SW, SG, and CC extracts prepared using SD were comparable to the previously reported yield $(2.6 \%)$ for the commercially available C. zeylanicum in Turkey (Sihoglu Tepe \& Ozaslan, 2020). Another finding showed a $352 \mathrm{mg} / \mathrm{g}$ yield for the freeze dried aqueous extract of C. zeylanicum and that was higher than the yield obtained in the current study (Takács et al., 2017). Species of Cinnamon, climate, growth condition, cultivation site, age of the bark, thickness of the bark and the density of the oil cells are positively correlated with the yield of the Cinnamon

Peer] reviewing PDF | (2020:04:48032:3:0:NEW 3 Sep 2020) 
242 essential oils ( $L i$, Kong \& Wu, 2013). Color of the bark, peeling ability, texture of the bark, odor

243 and the morphology of the leaves ware examined in SW and SG varieties (Ariyarathne,

244 Weerasuriya \& Senarath, 2018). However, scientific evidences regarding the bark thickness,

245 density of the oil cells of SW and SG have not been explored. Hence further investigations should

246 be conducted to evaluate the properties of the bark of these accessions.

247 The inhibitory activity for $\alpha$-glucosidase and $\alpha$-amylase varied depending on the sample and the

248 type of extraction. By comparing the $\alpha$-glucosidase and $\alpha$-amylase inhibitory activities of the

249 samples tested, the $\mathrm{IC}_{50}$ value of $\mathrm{SW}$, PWE exhibited the strongest inhibition compared to the

250 positive control, Acarbose. The methanolic extracts of Ceylon Cinnamon have been reported to

251 have the potential to control hyperglycemia (Nair, Kavrekar \& Mishra, 2013). The $\mathrm{IC}_{50}$ values

252 for the $\alpha$-amylase and $\alpha$-glucosidase inhibition were $130.55 \pm 10.50 \mu \mathrm{g} \mathrm{mL}^{-1}$ and $140.01 \pm 10.08$

$253 \mu \mathrm{g} \mathrm{mL}-1$, respectively for the $C$. zeylanicum methanol extracts. Another comparable $\alpha$-amylase

254 inhibition is reported for methanol extract of Cinnamon bark $\left(\mathrm{IC}_{50}: 86.84 \mu \mathrm{g} \mathrm{mL}^{-1}\right)$, Cinnamon

255 stick $\left(\mathrm{IC}_{50}: 54.69 \mu \mathrm{g} \mathrm{mL}-1\right)$ and the clinical drug, Metformin hydrochloride $(53.03 \mu \mathrm{g} \mathrm{mL}-1)$

256 (Wickramasinghe, 2018). According to the findings of Wickramasinghe et al. (2018), a poor $\alpha$ -

257 amylase inhibition was seen in Cinnamon drink $\left(3207.01 \mu \mathrm{g} \mathrm{mL}^{-1}\right)$, Cinnamon capsule (2537.49

$258 \mu \mathrm{g} \mathrm{mL}-1)$, and Cinnamon powder $\left(771.67 \mu \mathrm{g} \mathrm{mL}^{-1}\right)$. When compared with previously reported

259 values for methanolic extracts, the PWE and DWE of SW showed better enzyme inhibition $\left(\mathrm{IC}_{50}\right.$

260 for the $\alpha$-glucosidase inhibition; $42 \pm 8 \mu \mathrm{g} \mathrm{mL}^{-1}$ and $116 \pm 17 \mu \mathrm{g} \mathrm{mL}^{-1}$ and $\mathrm{IC}_{50}$ for the $\alpha$-amylase

261 inhibition; $78 \pm 7 \mu \mathrm{g} \mathrm{mL}^{-1}$ and $132 \pm 11 \mu \mathrm{g} \mathrm{mL}^{-1}$ respectively) The enzyme inhibition mechanism

262 of the Acarbose is well established. Acarbose inhibit the $\alpha$-glucosidase activity as a competitive

263 inhibitor (Van de Laar, 2008). However, phytochemicals in plant extracts mainly phenolics, act as

264 a non-competitive inhibitors against digestive enzymes. Non-competitive mode of inhibition is 
265 better due to the possible multiple side interactions of phenolic compounds with enzyme molecule

266 and also this type of inhibition does not depend on the substrate concentration.

267 Polyphenols, in particular proanthocyanidin polymers are a large groups of phytochemicals that

268 can be extracted from plants such as tea, coffee, wine, cocoa, grains, legumes, fruits and berries

269 (Chen et al., 2012). Several findings have confirmed that there is a positive correlation between

270 the antioxidant such as polyphenols present and the $\alpha$-glucosidase and $\alpha$-amylase inhibition. (Cai

271 et al., 2004; Peng et al., 2010; Abeysekera, Premakumara \& Ratnasooriya, 2013; Premakumara

272 et al., 2013) SW, DWE and PWE had high contents of PC and TPC, which can be correlated with

273 the observed better anti-diabetic activities (Table 2).

274 The effectiveness of phenolic compounds in inhibiting $\alpha$-amylase depends on the number and the 275 position of hydroxyl groups (Funke \& Melzig 2006). In the current study, a high amount of 276 phenolic compounds were extracted when water was used as a solvent and hence the extracts had 277 potent anti-diabetic properties.

278 GC-MS technique is a powerful and suitable tool for the determination of volatile compounds 279 because of its high separation efficiency and sensitive detection (Li, Kong \& Wu, 2013). 280 Cinnamaldehyde and Cinnamic acid are the major compounds of Cinnamon aqueous extracts 281 (Hafizur et al., 2015). The chemical composition in the aqueous extracts in our study, slightly 282 deviated from Hafizur et al., (2015) findings. Benzoic acid, Cinnamyl alcohol, Trans-Cinnamic 283 acid and 4-Allyl-2,6-dimethoxyphenol were the major compounds present in SW and SG aqueous 284 extracts. According to the findings of Hafizur et al., 2015, it is desirable to have high 285 concentrations of Cinnamic acid as it has the potential to decrease the blood glucose levels, 286 improve glucose tolerance and stimulate insulin secretion in diabetic rats in a time and dose 287 dependent manner. Hence, it is favorable to have extracts with high concentrations of Cinnamic 
288 acid for better diabetic control. Cinnamaldehyde is identified as the major compound present in

289 Cinnamon extracted using hydro distillation in several studies (Paranagama et al., 2001;

290 Kaskoos, 2019; Mota, Campelo \& Frota, 2019). The $\alpha$-amylase inhibition evaluated using a

291 combination of $(E)$-Cinnamaldehyde and $(E)$-Cinnamyl acetate has shown better potency than

292 Cinnamaldehyde alone (Sihoglu Tepe \& Ozaslan, 2020). The synergy between (E)-

293 Cinnamaldehyde and (E)-Cinnamyl acetate seems to be important for potent enzyme inhibition

294 Therefore, poor enzyme inhibition observed in SD and SE are consistent with the absence of $(E)$ -

295 Cinnamyl acetate. Higher amount of $(E)$-Cinnamaldehyde alone does not improve the enzyme

296 inhibitory potential. The inhibition by PWE of SW accession was higher due to the synergistic

297 effect of the compounds present in the extract.

298 Preparations of decoction is a common methods practiced in the preparation of Ayurveda drugs in

299 therapeutic regimen (Daswani et al., 2011). Pressurize water is an environmentally friendly non-

300 toxic novel method for effective extraction of plant metabolites without using organic solvents.

301 However, the most commonly practiced method for the extraction of Cinnamon is steam

302 distillation or hydro distillation. The loss of volatile compounds and long extraction times are some

303 of the drawbacks of steam distillation.

304 Super critical Carbon dioxide is an alternative used for the extraction of thermo sensitive 305 phytochemicals. However, in some studies supercritical carbon dioxide extracts have exhibited 306 low antioxidant activity compared to the ethanol extracts due to the low polarity of super critical 307 carbon dioxide as a solvent compared with ethanol (Singh et al., 2007).

308 Hence, there is an interest to develop new methods of extraction which could give better yields 309 and biological activity. Pressurized water extraction has the advantage of extracting polar 310 compounds from plant extracts hence can impart better biological activity (Jayawardena \& Smith, 
311 2010). In the current study the extract prepared using pressured water had the most potent anti-

312 diabetic activities. Further, low cost, safe for human consumption, short extraction times

313 compared to steam distillation are added advantages of pressurized water extractions.

\section{Conclusions}

315 Whilst there are numerous studies on the biological activity of essential oils, aspects such as safety, 316 astringency, cost and the solubility in water stifle their applications as nutraceuticals. This study 317 was mainly focused on investigating the in vitro hypoglycemic effects of aqueous extracts of 318 Cinnamon. This is in view of developing a safe, readily soluble Cinnamon extract for human 319 consumption that could effectively control hyperglycemia in diabetic individuals. Hence in the current study, the total phenolic content, proanthocyandins and essential oils were determined as

321 compounds largely responsible for the biologicals activities explored. The results showed that Sri

322 Wijaya Cinnamon water extract prepared using high pressure and the decoction method had the 323 highest anti-diabetic potential. The extracts have to be further purified and developed with in depth 324 studies using cell cultures and experimental animals for the treatment of diabetes mellitus.

\section{Acknowledgments}

327 Authors wish to thank Mr. A. T. Kannangara of the Department of Chemistry, University of 328 Kelaniya, Sri Lanka for his assistance in GC/MS analysis.

\section{References}

Abeysekera WPKM, Premakumara GAS, Ratnasooriya WD. 2013. In Vitro Antioxidant Blume). Tropical Agricultural Research 24:128-138. 
334

335

336

337

338

339

340

341

342

343

Alternate therapy of type 2 diabetes mellitus (T2DM) with nigella (Ranunculaceae). Journal of Medicinal Plant Research 5:6885-6889. DOI: 10.5897/JMPR11.1425.

Apostolidis E, Lee CM. 2010. In vitro potential of ascophyllum nodosum phenolic antioxidantmediated ??-glucosidase and ??-amylase inhibition. Journal of Food Science 75:97-102. DOI: 10.1111/j.1750-3841.2010.01544.x.

Ariyarathne HBMA, Weerasuriya SN, Senarath WTPSK. 2018. Comparison of morphological and chemical characteristics of two selected accessions and six wild species of genus $<$ em $>$ Cinnamomum $<$ em $>$ Schaeff. Sri Lankan Journal of Biology 3:11. DOI: 10.4038/sljb.v3i1.14.

Azad R, Senanayake G, Kumara KLW, Ranawaka RAAK, PushpaKumara DKNG, Wijesinghe KGG, Geekiyanage S. 2015. Morphological variation within progeny and deviations from mother plant reveal the allele richness in $<$ em $>$ Cinnamomum verum $<$ em $>$ germ-plasm: a case study from Deiyandara, Matara collection at the early vegetative stage. Tropical Agricultural Research and Extension 18:163. DOI: 10.4038/tare.v18i4.5380.

Cai Y, Luo Q, Sun M, Corke H. 2004. Antioxidant activity and phenolic compounds of 112 traditional Chinese medicinal plants associated with anticancer. Life Sciences 74:21572184. DOI: $10.1016 / j .1 f s .2003 .09 .047$.

Chen L, Sun P, Wang T, Chen K, Jia Q, Wang H, Li Y. 2012. Diverse Mechanisms of Antidiabetic E ff ects of the Di ff erent Procyanidin Oligomer Types of Two Di ff erent Cinnamon Species on db/db Mice.

Daswani PG, Ghadge AA, Brijesh S, Birdi TJ. 2011. Preparation of decoction of medicinal plants: A self-help measure? Journal of Alternative and Complementary Medicine 17:10991100. DOI: $10.1089 / \mathrm{acm} .2011 .0217$. 
357 Funke I, Melzig MF. 2006. Traditionally used plants in diabetes therapy: phytotherapeutics as

358 inhibitors of alpha-amylase activity. Revista Brasileira de Farmacognosia 16:1-5. DOI: 10.1590/S0102-695X2006000100002.

360

361

362

363

364

365

366

367

368

369

370

371

372

373

374

375

376

377

378

379

Hafizur RM, Hameed A, Shukrana M, Raza SA, Chishti S, Kabir N, Siddiqui RA, Hameed A. 2015. Panjwani Center for Molecular Medicine and Drug Research , International Center for Chemical. Phytomedicine. DOI: 10.1016/j.phymed.2015.01.003.

Jayawardena B, Smith RM. 2010. Superheated Water Extraction of Essential Oils from Cinnamomum zeylanicum ( L .). DOI: 10.1002/pca.1221.

Kaskoos RA. 2019. GC/MS Profile and in-vitro Antidiabetic Activity of Cinnamomum z eylanicum Blume., Bark and Trachyspermum ammi (L.) Sprague, Seeds . Journal of Essential Oil Bearing Plants 22:535-544. DOI: 10.1080/0972060x.2019.1612281.

Kazeem MI, Ogunbiyi J V, Ashafa AOT. 2013. In vitro Studies on the Inhibition of $\alpha$-Amylase and $\alpha$ - Glucosidase by Leaf Extracts of Picralima nitida ( Stapf ). 12:719-725.

Khan, A.; Safdar, M.; Khan, M. M. A.; Khattak, K. N. and Anderson R. 2003. Cinnamon Improves Glucose and Lipids of People With Type 2 Diabetes. 26.

van de Laar FA. 2008. Alpha-glucosidase inhibitors in the early treatment of type 2 diabetes. Vascular Health and Risk Management 4:1189-1195.

Lee HG, Jo Y, Ameer K, Kwon JH. 2018. Optimization of green extraction methods for cinnamic acid and cinnamaldehyde from Cinnamon (Cinnamomum cassia) by response surface methodology. Food Science and Biotechnology 27:1607-1617. DOI: 10.1007/s10068-018-0441-y.

Li Y, Kong D, Wu H. 2013. Analysis and evaluation of essential oil components of cinnamon barks using GC - MS and FTIR spectroscopy. Industrial Crops \& Products 41:269-278. 
DOI: $10.1016 /$ j.indcrop.2012.04.056.

381

382

383

384

385

386

387

388

389

390

391

392

393

394

395

396

397

398

399

400

401

402

Lokuge C.M.1, Weerathunge H.D., Abeysekera W.P.K.M., Premakumara G.A.S., Chandrathilake G.G.T. SDN. Comparative Study on Chemical Compositions of Bark and Leaf Essential Oils of Sri Wijeya and Sri Gemunu Cinnamon Varieties (Cinnamomum Zeylanicum Blume) Developed. :2018.

Mahmoodnia L, Aghadavod E, Rafieian-Kopaei M. 2017. Ameliorative impact of cinnamon against high blood pressure; an updated review. Journal of Renal Injury Prevention 6:171176. DOI: $10.15171 /$ jrip.2017.33.

Mota APP, Campelo TA, Frota CC. 2019. Evaluation of the antimicrobial activity of Cinnamomum zeylanicum essential oil and trans-cinnamaldehyde against resistant Mycobacterium tuberculosis. Bioscience Journal 35:296-306. DOI: 10.14393/BJv35n1a2019-41710.

Nair SS, Kavrekar V, Mishra A. 2013. In vitro studies on alpha amylase and alpha glucosidase inhibitory activities of selected plant extracts. European Journal of Experimental Biology $3: 128-132$.

Ouattara B, Simard RE, Holley RA, Piette GJ. 1997. Antibacterial activity of selected fatty acids and essential oils against six meat spoilage organisms. 37:155-162.

Peng X, Ma J, Chao J, Sun Z, Chang RCC, Tse I, Li ETS, Chen F, Wang M. 2010. Beneficial effects of cinnamon proanthocyanidins on the formation of specific advanced glycation endproducts and methylglyoxal-induced impairment on glucose consumption. Journal of Agricultural and Food Chemistry 58:6692-6696. DOI: 10.1021/jf100538t.

Premakumara GAS, Abeysekera WKSM, Ratnasooriya WD, Chandrasekharan N V., Bentota AP. 2013. Antioxidant, anti-amylase and anti-glycation potential of brans of some Sri 
403

404

405

406

407

408

409

410

411

Lankan traditional and improved rice (Oryza sativa L.) varieties. Journal of Cereal Science 58:451-456. DOI: 10.1016/j.jcs.2013.09.004.

Rahimi-Madiseh M, Malekpour-Tehrani A, Bahmani M, Rafieian-Kopaei M. 2016. The research and development on the antioxidants in prevention of diabetic complications. Asian Pacific Journal of Tropical Medicine 9:825-831. DOI: 10.1016/j.apjtm.2016.07.001.

Ranilla LG, Kwon YI, Apostolidis E, Shetty K. 2010. Phenolic compounds, antioxidant activity and in vitro inhibitory potential against key enzymes relevant for hyperglycemia and hypertension of commonly used medicinal plants, herbs and spices in Latin America. Bioresource Technology 101:4676-4689. DOI: 10.1016/j.biortech.2010.01.093.

Schwartz SS, Epstein S, Corkey BE, Grant SFA, Gavin JR, Aguilar RB. 2016. The time is right for a new classification system for diabetes: Rationale and implications of the $\beta$-cell-centric classification schema. Diabetes Care 39:179-186. DOI: 10.2337/dc15-1585.

SHEN Y, FUKUSHIMA M, ITO Y, MURAKI E, HOSONO T, SEKI T, ARIGA T. 2010. Verification of the Antidiabetic Effects of Cinnamon ( Cinnamomum zeylanicum ) Using Insulin-Uncontrolled Type 1 Diabetic Rats and Cultured Adipocytes . Bioscience, Biotechnology, and Biochemistry 74:2418-2425. DOI: 10.1271/bbb.100453.

Sihoglu Tepe A, Ozaslan M. 2020. Anti-Alzheimer, anti-diabetic, skin-whitening, and antioxidant activities of the essential oil of Cinnamomum zeylanicum. Industrial Crops and Products 145. DOI: 10.1016/j.indcrop.2019.112069.

Singh G, Maurya S, deLampasona MP, Catalan CAN. 2007. A comparison of chemical, antioxidant and antimicrobial studies of cinnamon leaf and bark volatile oils, oleoresins and their constituents. Food and Chemical Toxicology 45:1650-1661. DOI: 10.1016/j.fct.2007.02.031. 
426 Takács I, Takács Á, Pósa A, Gyémánt G. 2017. HPLC method for Measurement of human 427 salivary $\alpha$-Amylase inhibition by aqueous plant extracts. Acta Biologica Hungarica 68:127136. DOI: $10.1556 / 018.68 .2017 .2 .1$.

429 Toda S. 2005. Fragmentation by Copper - Hydrogen Peroxide In Vitro. Journal of Medicinal $430 \quad$ Food 8:266-268.

431 W. T. H. C. Wickramasinghe 1 LDCP 3 and CP. 2019. Cinnamomum verum (cinnamon). 9:4674-4681. DOI: 10.13040/IJPSR.0975-8232.9(11).4674-81.

433

434

435

436

437

438

439

440

441

442

443

444 445

Wang Y, Huang S, Shao S, Qian L, Xu P. 2012. Studies on bioactivities of tea (Camellia sinensis L.) fruit peel extracts: Antioxidant activity and inhibitory potential against ??-glucosidase and ??-amylase in vitro. Industrial Crops and Products 37:520-526. DOI: 10.1016/j.indcrop.2011.07.031.

William J, John P, Mumtaz MW, Ch AR, Adnan A, Mukhtar H, Sharif S, Raza SA, Akhtar MT. 2019. Antioxidant activity, $\alpha$-glucosidase inhibition and phytochemical profiling of Hyophorbe lagenicaulis leaf extracts. PeerJ 2019:1-16. DOI: 10.7717/peerj.7022.

Wong YC. 2014. Extraction of Essential Oil from Cinnamon ( Cinnamomum zeylanicum ).

Zaid H, Saad B, Mahdi AA, Tamrakar AK, Haddad PS, Afifi FU. 2015. Medicinal Plants and Natural Active Compounds for Diabetes and/or Obesity Treatment. Evidence-based Complementary and Alternative Medicine 2015:2-3. DOI: 10.1155/2015/469762.

https://www.lankabusinessonline.com/sri-lanka-develops-new-cinnamon-varieties/ (2020.04.07) 


\section{Table $\mathbf{1}$ (on next page)}

$\mathrm{IC}_{50}$ for $\alpha$-glucosidase and $\alpha$-amylase of SW, SG and CC, extracted by different methods.

Each data point represents the mean of three replicates \pm SEM. Mean values in each column, in each cinnamon accessions followed by the same letter, are not significantly different $(p \geq 0.05)$ by Tukey's multiple range comparison tests.

SW, Sri Wijaya cinnamon accession; SG, Sri Gemunu cinnamon accession; CC, commercially available Cinnamomum zeylanicum; SE, Solvent Extraction; SD, Steam Distillation; MD, Microwave Digestion; DWE, Decoction Water Extraction; IWE, Infusion Water Extraction; PWE, Pressurized Water Extraction 
1 Table 1:

2 IC $_{50}$ for $\alpha$-glucosidase and $\alpha$-amylase of SW, SG and CC, extracted by different methods.

3

\begin{tabular}{lll}
\hline Extraction methods & $\begin{array}{l}\mathrm{IC}_{50} \text { for } \alpha \text {-glucosidase } \\
\left.\mathrm{mL}^{-1}\right)\end{array}$ & $\left.\begin{array}{l}\mu \mathrm{g} \\
\mathrm{IC}_{50} \\
\mathrm{~mL}^{-1}\end{array}\right)$
\end{tabular} for $\alpha$-amylase $(\mu \mathrm{g}$

\begin{tabular}{|c|c|c|c|}
\hline \multirow{2}{*}{4} & \multicolumn{3}{|c|}{ "SW" } \\
\hline & SE & $650 \pm 121^{c}$ & $615 \pm 99^{c}$ \\
\hline & SD & $150 \pm 5^{\mathrm{ab}}$ & $172 \pm 9^{b}$ \\
\hline 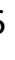 & MD & $160 \pm 14^{b}$ & $192 \pm 7^{b}$ \\
\hline & DWE & $116 \pm 17^{\mathrm{ab}}$ & $132 \pm 11^{\mathrm{ab}}$ \\
\hline 5 & IWE & $144 \pm 31^{\mathrm{ab}}$ & $171 \pm 14^{b}$ \\
\hline & PWE & $42 \pm 13^{a}$ & $78 \pm 7^{\mathrm{a}}$ \\
\hline 7 & Acarbose & $173 \pm 7^{b}$ & $95 \pm 4^{\mathrm{a}}$ \\
\hline
\end{tabular}

"SG"

$8 \mathrm{SE}$

SD

MD

9

DWE

IWE

10 PWE

Acarbose
$785 \pm 124^{c}$

$165 \pm 5^{\mathrm{ab}}$

$182 \pm 6^{\mathrm{b}}$

$121 \pm 5^{\mathrm{a}}$

$149 \pm 2^{\mathrm{a}}$

$72 \pm 3^{\mathrm{ab}}$

$173 \pm 7^{\mathrm{b}}$

$708 \pm 77^{\mathrm{d}}$

$180 \pm 7^{\mathrm{c}}$

$215 \pm 12^{c}$

$143 \pm 16^{\text {bc }}$

$169 \pm 17^{\mathrm{c}}$

$186 \pm 10^{\mathrm{b}}$

$95 \pm 4^{\mathrm{a}}$

11

CC

SE

$606 \pm 139^{\mathrm{e}}$

$201 \pm 5^{\mathrm{c}}$

12 SD

$296 \pm 25^{\text {d }}$

$120 \pm 5^{b}$

MD

$159 \pm 6^{\mathrm{b}}$

$111 \pm 2^{\mathrm{a}}$

13

DWE

$162 \pm 8^{\mathrm{b}}$

$260 \pm 13^{\mathrm{d}}$

IWE

$129 \pm 9^{\mathrm{a}}$

$246 \pm 17^{\mathrm{d}}$

PWE

$132 \pm 5^{\mathrm{a}}$

$88 \pm 7^{\mathrm{a}}$

Acarbose

$173 \pm 7^{b}$

$95 \pm 4^{\mathrm{a}}$ 
16 Each data point represents the mean of three replicates \pm SEM. Mean values in each column, in

17 each cinnamon varieties followed by the same letter, are not significantly different $(\mathrm{p} \geq 0.05)$ by

18 Tukey's multiple range comparison tests. ${ }^{1}$

19

${ }^{1} \mathrm{SW}$, Sri Wijaya cinnamon accession; SG, Sri Gemunu cinnamon accession; CC, commercially available Cinnamomum zeylanicum; SE, Solvent Extraction; SD, Steam Distillation; MD, Microwave Digestion; DWE, Decoction Water Extraction; IWE, Infusion Water Extraction; PWE, Pressurized Water Extraction 


\section{Table 2 (on next page)}

TPC and PC from quills of CC, SW and SG, with different extraction methods.

Each data point represents the mean of three replicates \pm SD. Mean values in each column, in each cinnamon accessions followed by the same letter, are not significantly different $(p \geq 0.05)$ by Tukey's multiple range comparison tests.

SW, Sri Wijaya cinnamon accession; SG, Sri Gemunu cinnamon accession; CC, commercially available Cinnamomum zeylanicum; SE, Solvent Extraction; SD, Steam Distillation; MD, Microwave Digestion; DWE, Decoction Water Extraction; IWE, Infusion Water Extraction; PWE, Pressurized Water Extraction 
1 Table 2:

2 TPC and PC from quills of CC, SW and SG, with different extraction methods.

\begin{tabular}{|c|c|c|c|c|c|c|}
\hline \multirow{2}{*}{$\begin{array}{l}\text { Extraction } \\
\text { methods }\end{array}$} & \multicolumn{3}{|c|}{ TPC (mg GAE/g) } & \multicolumn{3}{|c|}{ PC (mg of catechin equivalent $\mathrm{g}^{-1}$ ) } \\
\hline & "SW" & "SG" & $\mathrm{CC}$ & "SW" & "SG" & $\mathrm{CC}$ \\
\hline SE & $0.90 \pm 0.01^{\mathrm{e}}$ & $0.65 \pm 0.01^{\mathrm{d}}$ & $0.90 \pm 0.01^{\mathrm{b}}$ & $5.12 \pm 0.01^{\mathrm{b}}$ & $3.56 \pm 0.01^{\mathrm{b}}$ & $7.34 \pm 0.01^{\mathrm{c}}$ \\
\hline SD & $0.21 \pm 0.01^{\mathrm{a}}$ & $0.15 \pm 0.07^{b}$ & $0.68 \pm 0.01^{\mathrm{a}}$ & $3.00 \pm 0.01^{\mathrm{a}}$ & $1.00 \pm 0.01^{\mathrm{a}}$ & $5.65 \pm 0.01^{\mathrm{a}}$ \\
\hline MD & $0.67 \pm 0.01^{\mathrm{c}}$ & $0.12 \pm 0.01^{\mathrm{a}}$ & $1.73 \pm 0.02^{\mathrm{d}}$ & $15.00 \pm 0.01^{\mathrm{c}}$ & $12.00 \pm 0.01^{\mathrm{c}}$ & $6.14 \pm 0.01^{b}$ \\
\hline DWE & $2.24 \pm 0.00^{\mathrm{f}}$ & $1.00 \pm 0.00^{\mathrm{f}}$ & $0.91 \pm 0.01^{\mathrm{b}}$ & $40.05 \pm 0.10^{\mathrm{f}}$ & $26.00 \pm 0.09^{\mathrm{f}}$ & $17.5 \pm 0.01^{\mathrm{d}}$ \\
\hline IWE & $0.87 \pm 0.01^{\mathrm{d}}$ & $0.83 \pm 0.01^{\mathrm{e}}$ & $1.51 \pm 0.05^{\mathrm{c}}$ & $27.21 \pm 0.07^{\mathrm{d}}$ & $21.78 \pm 0.09^{\mathrm{e}}$ & $32.77 \pm 0.01^{\mathrm{e}}$ \\
\hline PWE & $1.53 \pm 0.01^{\mathrm{b}}$ & $0.18 \pm 0.01^{\mathrm{c}}$ & $2.90 \pm 0.08^{\mathrm{e}}$ & $36.08 \pm 0.01^{\mathrm{e}}$ & $17.21 \pm 0.01^{\mathrm{d}}$ & $7.39 \pm 0.03^{c}$ \\
\hline
\end{tabular}

3 Each data point represents the mean of three replicates \pm SD. Mean values in each column, in each

4 cinnamon accessions followed by the same letter, are not significantly different $(\mathrm{p} \geq 0.05)$ by

5 Tukey's multiple range comparison tests. ${ }^{1}$

\footnotetext{
${ }^{1} \mathrm{SW}$, Sri Wijaya cinnamon accession; SG, Sri Gemunu cinnamon accession; CC, commercially available Cinnamomum zeylanicum; SE, Solvent Extraction; SD, Steam Distillation; MD, Microwave Digestion; DWE, Decoction Water Extraction; IWE, Infusion Water Extraction; PWE, Pressurized Water Extraction
} 


\section{Table 3(on next page)}

Chemical compositions of extracts from CC. SW and SG, by various extraction methods.

Each data point represents the mean of three replicates.

SW, Sri Wijaya cinnamon accession; SG, Sri Gemunu cinnamon accession; CC, commercially available Cinnamomum zeylanicum; 1, Solvent Extraction; 2, Steam Distillation; 3, Pressurized Water Extraction; 4, Decoction Water Extraction; 5, Infusion Water Extraction 
2 Chemical compositions of extracts from CC. SW and SG, by various extraction methods.

\begin{tabular}{|c|c|c|c|c|c|c|c|c|c|c|c|c|c|c|c|}
\hline \multirow{3}{*}{ Compounds } & \multicolumn{5}{|c|}{ SG } & \multicolumn{5}{|c|}{$\mathbf{C C}$} & \multicolumn{5}{|c|}{ SW } \\
\hline & \multicolumn{15}{|c|}{ Area percentage $(\%)$} \\
\hline & 1 & 2 & 3 & 4 & 5 & 1 & 2 & 3 & 4 & 5 & 1 & 2 & 3 & 4 & 5 \\
\hline 3-carene & - & - & - & - & - & 0.2 & - & - & - & - & - & - & - & - & - \\
\hline Cymol & - & - & - & 0.89 & - & - & - & - & - & - & - & - & 0.16 & - & - \\
\hline Benzoic acid & - & - & 1.6 & 2.58 & - & - & - & - & - & - & - & - & 15.49 & 22.51 & 0.81 \\
\hline Benzyl alcohol & - & - & 0.17 & - & - & - & - & 0.42 & - & - & - & - & 3.8 & 3.98 & - \\
\hline Undecane & - & - & 0.46 & - & - & & & & & & & - & 1.1 & - & - \\
\hline Methyl salicylate & - & - & 0.26 & - & 2.34 & & - & 13.52 & 10.35 & - & & - & 0.42 & - & 5.24 \\
\hline Terpinen-4-ol & - & 1.36 & - & - & - & 0.48 & 0.41 & - & - & - & 0.78 & 0.44 & - & - & - \\
\hline Naphthalene & - & - & - & - & - & 0.19 & - & - & - & - & - & - & - & - & - \\
\hline Linalool & - & 5.17 & - & - & - & 2.6 & 2.07 & - & - & 0.31 & 1.07 & 2.21 & - & - & - \\
\hline Benzcatechin & - & & & & & & & & & & & - & 1.14 & - & - \\
\hline$\beta$-Fenchyl alcohol & - & & & & & & 0.77 & - & & 0.31 & & 0.81 & - & - & - \\
\hline Benzenepropanal & - & 1.68 & - & - & - & 0.14 & 0.41 & - & 0.35 & 0.24 & 0.14 & 0.43 & - & - & - \\
\hline Benzenepropanol & - & - & 1.2 & 2 & 0.74 & & - & 0.29 & & 0.46 & 0.19 & - & 0.54 & - & 0.34 \\
\hline 3-cyclohexene-1-methanol & - & - & - & - & - & 0.69 & - & - & - & - & - & - & - & - & - \\
\hline Salicylic acid & - & - & - & - & - & - & - & 12.93 & 4.05 & - & - & - & - & - & - \\
\hline Acetic acid, cinnamyl ester & - & - & - & - & - & - & 6.05 & 1.74 & 1.85 & - & - & 2.85 & - & - & - \\
\hline (E)-cinnamaldehyde & 43 & 65.21 & 5.8 & 34.6 & 55.72 & 48.77 & 79.06 & 43.41 & 57.7 & 73.25 & 39.24 & 38.85 & 5.46 & 5.58 & 40.48 \\
\hline Benzaldehyde & - & - & - & - & - & - & - & - & - & - & - & 0.07 & - & - & - \\
\hline 1-phellandrene & - & - & - & - & - & 1.28 & - & - & - & - & - & 0.09 & - & - & - \\
\hline (E)- 2,3-epoxycarane & - & - & - & 0.83 & - & - & - & - & - & - & - & - & - & - & - \\
\hline Dimethylsulfonium dicyanomethylide & - & - & - & 0.4 & - & - & - & - & - & - & - & - & - & - & - \\
\hline 2,4-Dimethyl-2,4-pentadien-1-ol & - & - & - & 1.58 & - & - & - & - & - & - & - & - & - & - & - \\
\hline Eugenol & 8 & 2.47 & 0.33 & 0.59 & 1.82 & 1.94 & 6.75 & 7.85 & 7.67 & 8.83 & 14.67 & 12.51 & 1.74 & 1.27 & 6.55 \\
\hline Cinnamaldehyde dimethyl acetal & - & - & 11.84 & 5.3 & 18.53 & 6.2 & - & 0.54 & 0.32 & 2.06 & 0.49 & - & 0.39 & - & 5.74 \\
\hline Vanillylmandelic acid & - & - & 0.78 & - & - & - & - & - & - & - & - & - & 0.78 & - & - \\
\hline Trans-Cinnamic acid & - & - & 0.14 & 16.86 & 2.07 & - & - & - & - & - & - & - & 1.74 & 4.51 & 0.92 \\
\hline O-methoxy-Cinnamaldehyde & - & 0.65 & 0.95 & 2.04 & 1.78 & 1.97 & 1.79 & - & 1.52 & 2 & 2.62 & 2.18 & 2.04 & 2.14 & 3.57 \\
\hline
\end{tabular}


Para methoxy cinnamic aldehyde Propanoic acid, phenylmethyl ester 1,2-Dihydroxy-4-(1-propyl)benzene Benzyl benzoate

Sabinene

$\gamma$-terpinene

Cinnamyl alcohol

Phenylpropyl acetate,

Copaene

Caryophyllenyl alcohol

(+) Spathulenol

Caryophyllene

trans-Cinnamyl acetate

(+)-(1S,3R,4S)-4(a)-Methyladamantane 1-(2'-hydroxyphenyl)prop-2-en-1-ol (1S,2S,6S,8S)-11-(Hydroxymethyl)-6methyl-3

methylenetricyclo[6.3.0.0(2,6)] undec

1,3,5-benzenetriol

4-propyl-1,2-Benzenediol

Benzenemethanol

Caryophyllene oxide

Allylbenzene

3-Phenylprop-2-yn-1-ol

1-(Trideuteriosylanyl)-benzene

Methoxy-phenyl-Oxime

Cineole

3,7-dimethyl-1,6-octadien-3-ol

a-terpinolene

O-Methoxyphenol

Vinyl phenyl carbinol

Ethyl benzenecarboxylate

2H-1-benzopyran

2-methoxy-4-propyl-Phenol

Benzenepropyl acetate

Homo - syringaldehyde

\begin{tabular}{|c|c|c|c|c|c|c|c|c|c|c|c|c|c|c|}
\hline- & & & & & & - & 1.66 & 1.85 & 0.36 & - & - & - & - & - \\
\hline - & - & - & 0.4 & - & - & - & - & - & - & - & - & - & - & - \\
\hline _ & - & - & 0.86 & - & - & - & - & - & - & - & - & - & - & - \\
\hline 20 & 1.17 & - & 0.6 & 0.39 & 3.42 & 2.69 & 0.33 & 1.52 & 0.62 & 5.78 & 6.29 & - & 1.15 & 1.74 \\
\hline- & 0.97 & - & - & - & - & - & - & - & - & - & 0.1 & - & - & - \\
\hline- & - & - & 0.42 & - & 0.24 & - & - & - & - & - & 0.11 & - & - & - \\
\hline 1 & 0.72 & 32.44 & 21.3 & 10.87 & 0.7 & - & - & - & 6.15 & 5.55 & 0.66 & 40.08 & 42.28 & 14.32 \\
\hline- & - & - & - & - & - & - & - & - & - & 0.61 & - & - & - & - \\
\hline- & - & - & - & - & 0.46 & - & - & - & - & - & - & - & - & - \\
\hline- & - & - & - & - & 0.33 & - & - & - & - & - & - & - & - & - \\
\hline- & - & - & - & - & 0.24 & - & - & - & - & - & - & - & - & - \\
\hline 3 & - & - & 0.51 & - & 4.33 & - & - & - & - & 0.26 & - & - & - & - \\
\hline 23 & 19.85 & - & - & 3.52 & 3.85 & - & - & & 2.09 & 25.39 & 28.59 & 0.13 & - & 9.73 \\
\hline- & - & - & - & - & - & - & - & - & - & - & - & 2.14 & - & - \\
\hline- & - & - & - & - & - & - & - & - & - & - & - & 0.71 & - & - \\
\hline- & - & - & - & - & - & - & - & - & - & - & - & 0.1 & - & - \\
\hline- & - & - & - & - & - & - & - & - & - & - & - & 1.11 & - & - \\
\hline- & - & - & - & - & - & - & - & - & - & - & - & 1.61 & - & - \\
\hline- & - & - & - & - & & - & - & & 0.18 & 0.17 & - & - & - & 0.08 \\
\hline- & - & - & - & - & 2.18 & - & - & - & - & - & 0.11 & - & - & - \\
\hline- & - & - & - & - & - & - & - & - & - & - & - & - & - & 0.18 \\
\hline- & - & - & - & - & - & - & - & - & 0.2 & - & - & - & - & - \\
\hline- & - & - & - & - & - & - & - & - & 0.16 & - & - & - & - & - \\
\hline- & - & - & - & - & - & - & - & - & - & - & 0.04 & - & - & - \\
\hline- & - & - & - & - & - & - & - & - & - & - & 0.04 & - & - & - \\
\hline- & - & - & - & - & - & - & - & - & - & - & 0.26 & - & - & - \\
\hline- & - & - & - & - & - & - & - & - & - & - & 0.41 & - & - & 0.07 \\
\hline - & - & - & - & - & - & - & - & - & - & & 0.1 & - & - & - \\
\hline - & - & - & - & - & - & - & - & - & - & 0.08 & 0.16 & - & - & - \\
\hline- & - & - & - & - & - & - & - & - & - & & 0.07 & - & - & - \\
\hline- & - & - & - & - & - & - & - & - & - & & 0.06 & - & - & - \\
\hline - & - & - & - & - & - & - & - & - & - & & 0.12 & - & - & - \\
\hline - & - & - & - & - & - & - & - & - & - & & 0.79 & - & - & - \\
\hline - & - & - & - & - & - & - & - & - & - & & 0.04 & - & - & - \\
\hline
\end{tabular}


Ortho methoxy cinnamyl acetate

Oxalic acid, 2-phenylethyl propyl ester

Benzyl salicylate

Methyl palmitate

Linoleic acid

3,4,5-trimethoxyphenol

Benzaldehyde, 4-hydroxy-3,5-

dimethoxy-

3-Methoxy-4-hydroxycinnamaldehyde 4-((1E)-3-Hydroxy-1-propenyl)-2-

methoxyphenol

3-Phenylprop-2-yn-1-ol

Salicylic acid

Formic acid, 3-phenylpropyl ester

4,2,8-Ethanylylidene-2H-1-benzopyran, octahydro-2-methyl-

1-Methoxy-7-methyl-3,4-

dihydrobenzo[c]pyran

2,6-dimethoxy-4-(2-propenyl)-Phenol,

Butylated hydroxytoluene

Trans-3-Pinen-2-ol [2,6,6-

trimethylbicyclo[3.1.1]hept-3-en-2-ol]

4-Allyl-2,6-dimethoxyphenol

4,7-Dihydro-4,7-methano-2H-indole

Palmitic acid

4,4,8-

Trimethyltricyclo[6.3.1.0(1,5)]dodecane-

2,9-diol

3-Methoxy-4-hydroxycinnamaldehyde

Styrene

Camphene

1-Methyl-2-isopropylbenzene

Dodecane

3,4,4-Trimethyl-2-pentenal

2-methylene-Cyclohexanol

1,5,9,9-tetramethyl-, Z,Z,Z-1,4,7,-

$\begin{array}{cccc}10.2 & 3.24 & 0.92 & - \\ - & - & - & - \\ - & 0.44 & - & 1.53 \\ - & 0.8 & - & -\end{array}$

$\begin{array}{ccc}1.79 & 1.05 & 1.7 \\ 0.5 & & - \\ - & - & - \\ - & - & -\end{array}$

0.36

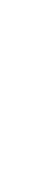

-
-
-
-

$\begin{array}{ccc}0.77 & 12.71 & 8.79 \\ 0.05 & - & - \\ - & 0.27 & -\end{array}$


Cycloundecatriene,

\section{$\Delta$-Cadinene}

Hydrocinnamic acid

Phenol, 2,6-bis(1,1-dimethylethyl)-

(S)-(+)-5-sec-Butyl-2-pyrimidinol

Spiro[2-ethylidene-3-

methylcyclohexane]oxirane

1-Methoxy-7-methyl-3,4-

dihydrobenzo[c]pyran

Aspirin methyl ester

1H-Pyrrole-2,4-dicarboxylic acid, 3,5-

dimethyl-, diethyl ester

Hexadecanoic acid

$\begin{array}{ccc}- & - & - \\ - & - & 0.2 \\ - & - & 0.09 \\ - & - & 0.56 \\ - & - & 1.96 \\ - & - & - \\ - & - & - \\ - & - & -\end{array}$

$\alpha$-Thujene

4 Each data point represents the mean of three replicates. ${ }^{1}$

${ }^{1} \mathrm{SW}$, Sri Wijaya cinnamon accession; SG, Sri Gemunu cinnamon accession; CC, commercially available Cinnamomum zeylanicum; 1, Solvent Extraction; 2, Steam Distillation; 3, Pressurized Water Extraction; 4, Decoction Water Extraction; 5, Infusion Water

Extraction 


\section{Figure 1 (on next page)}

Yields (\%, w/w, dry basis) of compounds in extracts from different cinnamon quills with different extraction methods $(n=3)$.

Mean values in each extraction methods, in each cinnamon varieties followed by the same letter, are not significantly different ( $p \geq 0.05$ ) by Tukey's multiple range comparison tests. Black: SW, Sri Wijaya cinnamon accession; Whitish gray: SG, Sri Gemunu cinnamon accession; Gray: CC, commercially available Cinnamomum zeylanicum; SE, Solvent Extraction; SD, Steam Distillation; MD, Microwave Digestion; DWE, Decoction Water Extraction; IWE, Infusion Water Extraction; PWE, Pressurized Water Extraction 


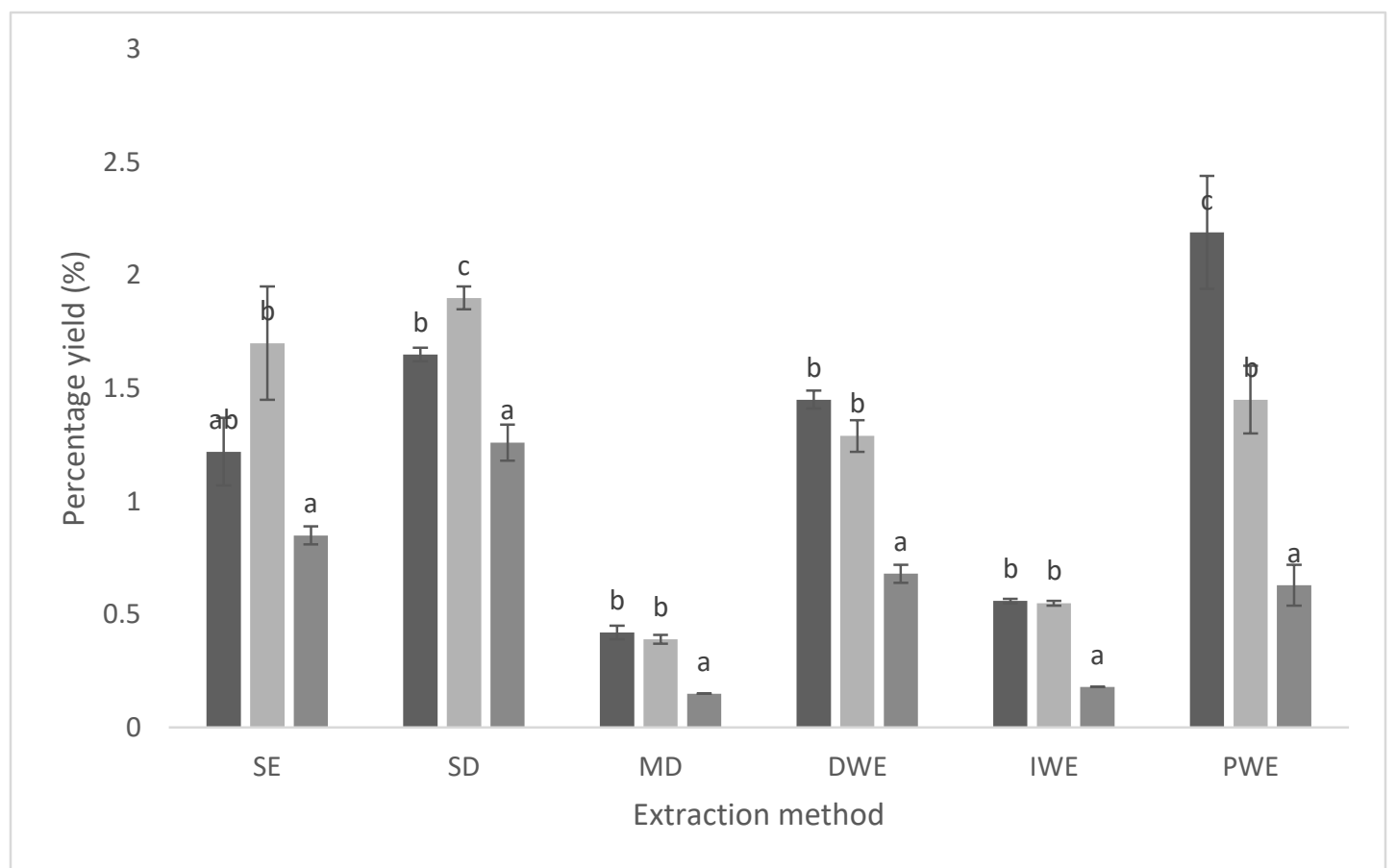

